\title{
Product Development of Les Merveilleuses LADURÉE Cosmetics and Customer Experience
}

\author{
Shoichi Kobayashi ${ }^{1}$, Takao Someya ${ }^{1}$, Shin'ya Nagasawa ${ }^{2}$ \\ ${ }^{1}$ ALBION Co., Ltd., 1-7-10 Ginza, Chuo-ku Tokyo, Japan Tokyo, Japan \\ ${ }^{2}$ Graduate School of Commerce, Waseda University, Nishiwaseda, shinjyuku-ku, Japan
}

\section{Email address:}

ta_someya@albion.co.jp (T. Someya)

\section{To cite this article:}

Shoichi Kobayashi, Takao Someya, Shin'ya Nagasawa. Product Development of Les Merveilleuses LADURÉE Cosmetics and Customer Experience. Science Journal of Business and Management. Special Issue: Customer Experience Management/MarketingBranding. Vol. 3, No. 2-1, 2015, pp. 60-62. doi: 10.11648/j.sjbm.s.2015030201.17

\begin{abstract}
LADURÉE, a French manufacturer of high-grade Western confectioneries, and ALBION, a Japanese manufacturer of high-grade cosmetics, collaborated to develop and release a new cosmetic product series. These products became popular in the stagnant Japanese cosmetic industry. This study analyzed these products from the viewpoint of Bernd H. Schmitt's customer experience marketing. Consequently, each module was found to possess a high level of customer experience, which was a primary factor in the series' popularity.
\end{abstract}

Keywords: LADURÉE, Cosmetics, Customer Experience

\section{Introduction}

ALBION Corporation released a makeup cosmetics series in January 2012 that was a collaboration with LADURÉE, a famous, well-established French manufacturer of high-grade Western confectioneries. These cosmetics were highly successful; for example, people waited for two hours to purchase them on the release date. This product development was analyzed from the viewpoint of affective experience, particularly Bernd $\mathrm{H}$. Schmitt's customer experience marketing. Consequently, the authors judged that this customer experience analysis is a suitable method to logically explain a product's appeal and the primary factors for its popularity.

\section{Les Merveilleuses LADURÉE}

As described above, Les Merveilleuses LADURÉE is a cosmetic brand established by LADURÉE and ALBION Corporation. It combines the corporate philosophy of LADURÉE - "Only things that instinctively charm women can be called truly beautiful," which fundamentally evokes images of Western confectioneries in Paris, France during the halcyon days of the $18^{\text {th }}$ and $19^{\text {th }}$ centuries-with the concept of the "Merveilleuses."

"Merveilleuses" refers to the Parisiennes in the upper echelons of French society after the French Revolution in the $19^{\text {th }}$ century, who threw off strict morality based on the politics of fear, seeking freedom and liberation, to live in the most beautiful and active way possible. In French "merveilleuses" may mean "splendid" or "eccentric." It refers to the lifestyle of those women who live in the most refined environments with intense passion that can be considered revolutionary for its time; such a lifestyle is detached from the mundane and ordinary.

\section{Symbolic Product}

Based on the underlying philosophy of Les Merveilleuses LADURÉE cosmetics, the product concepts were formulated as follows:

- Thoroughly thought out items that enable rich self-expression

- A sense of use that appeals to all five senses and will remain in one's memory after even a single touch

- Functional beauty that is realized even in the elegant movements of women

- A product concept with a sense of a story to be told

Therefore, products involving technical innovation to produce these surprising elements were required in addition to the obvious values and quality of cosmetics (beauty and attractiveness). 
To that end, because Les Merveilleuses as an aesthetic symbol actually applied blush to their cheeks, the central item in this series has been set as the cheeks. Around the turn of the $19^{\text {th }}$ century, cosmetics were not as developed as they are today. Women applied rose petals and other pigment-containing plants to their skin, just like women apply blush today. That is why a blush product in the shape of rose petals was created. This product had an innovative quality not realizable using traditional cosmetic technologies. Within the product series - which carries the initial impression of a simple cosmetics line-technical innovation made great contributions. This brand new type of blush was suitable as a frank expression of the product concept described above, and served as a symbol of the series. FACE COLOR ROSE LADURÉE is shown in Figure 1

\section{Results of Success Factor Analysis Via Customer Experience}

This series was different from traditional marketing, in which the price of a cosmetic is primarily determined by its functionality and benefits, which determines demand and supply. It is a representative example of a so-called "sensitivity product" that appeals to one's sensations and emotions. Therefore, as shown in the 4P analysis, the fact that the share was reliably improved for this product-while maintaining the business style of no mass promotion and using only limited distribution channels - cannot be fully explained from aspects of traditional marketing. Accordingly, it was thought that a detailed analysis based on customer experience marketing was instead required.

To that end, an analysis was attempted (Table 1) according to Strategic Experiential Modules (SEM), the conceptual framework of Bernd $\mathrm{H}$. Schmitt's customer experience marketing. The various modules were considered regarding the customer experience of Les Merveilleuses LADURÉE cosmetics. The results of the $4 \mathrm{P}$ analysis are shown in Table 1, and the customer experience analysis results in Table 2 .

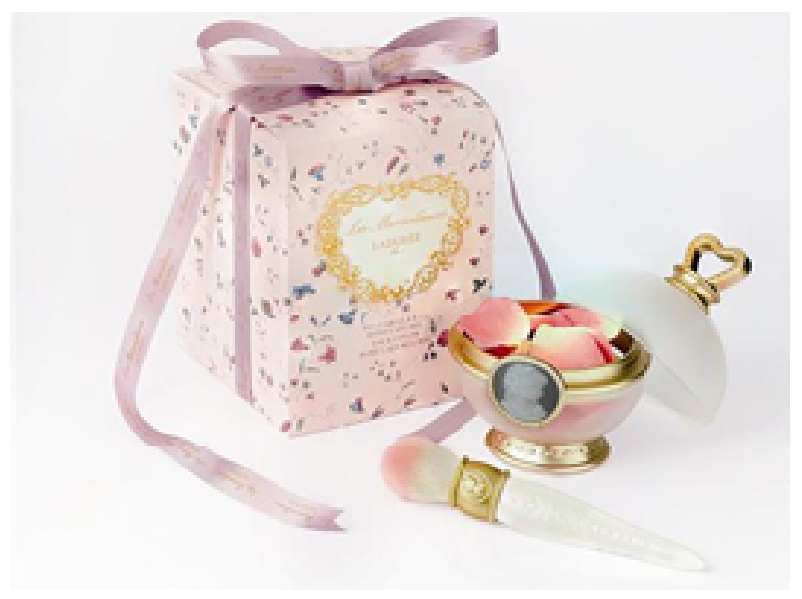

Figure 1. Face color rose ladurée.
Table 1. LADURÉE (cosmetics) 4 P analysis.

\begin{tabular}{|c|c|}
\hline 4Ps & LADURÉE (cosmetics) \\
\hline \multirow[b]{2}{*}{ Product } & - High-grade cosmetics \\
\hline & $\begin{array}{l}\text { High-quality, innovative product series with } \\
\text { characteristic blush }\end{array}$ \\
\hline \multirow{3}{*}{ Price } & - High prices \\
\hline & - FACE COLOR ROSE LADURÉE: 10,000 yen \\
\hline & - Only at specialty shops and department stores \\
\hline Place & $\begin{array}{l}\text { - Total of } 17 \text { stores: eight department stores, five specialty } \\
\text { shops, and four overseas stores }\end{array}$ \\
\hline \multirow{3}{*}{ Promotion } & - No mass promotion \\
\hline & - Proactive publicity \\
\hline & - Proactive utilization of social media \\
\hline
\end{tabular}

Table 2. LADURÉE (cosmetics) customer experience according to Bernd H. Schmitt's SEM.

\begin{tabular}{ll}
\hline Module & Customer experience \\
sense & - Creating products that appeal to all five senses \\
& - Visually creating the ornate atmosphere of the $19^{\text {th }}$ century \\
& from the point-of-sale environs to furniture and fixtures \\
& - France's sophisticated beauty, elegance, worldview, and \\
feel & sense of the seasons \\
& - The store interior design beckons visitors from the real \\
& world to the lifestyle of the French upper class \\
think & - Creating products with a high degree of difficulty based \\
& on the development concept of the "beautiful betrayal" \\
act & - Efforts made toward recalling French culture and lifestyle \\
relate & - Cosmetics practices focused on the cheeks \\
& - Connections with fans via the Internet
\end{tabular}

\section{Discussion}

The analysis of Les Merveilleuses LADURÉE cosmetics from the perspective of customer experience revealed that ratings were high for all of Bernd $\mathrm{H}$. Schmitt's five customer experience categories (SENSE, FEEL, THINK, ACT, and RELATE). One can say that these cosmetics are assemblages of customer experience.

Regarding the intellectual customer experience (THINK) in particular, it is thought that the purposeful choice of the name "Les Merveilleuses" was unique in that it was fundamentally based on the value of the LADURÉE Western confectioneries brand in its market expansion from Western-style sweets to cosmetics. Other unique points were the addition of technical innovation and creation of an independent worldview for these cosmetics.

\section{References}

[1] Bernd H.Schmitt; Experiential Marketing: How to Get Customers to Sense, Feel, Think, Act, Relate; Free Press, 1999

[2] Bernd H. Schmitt Customer Experience Management; A Revolutionary Approach to Connecting with Your Customers; Wiley, 2003

[3] Shin'ya Nagasawa, editor, Waseda University Business School, Nagasawa Research Laboratories (Taro Yamamoto, Masahiko Yoshida, Yusuke Irisawa, Tsunehiro Yamamoto, Shinji Enoki): Hitmaking With Experiential Marketing - Manufacturing that Rocks the Boat, Nikka Giren Publishing, 2005. 
[4] Shin'ya Nagasawa, editor: Creation of Experience Value in Long-Established Businesses - Customer Approach Management, Doyukan, 2006.

[5] Shin'ya Nagasawa, editor: Producing Experience Value, Nikka Giren Publishing, 2007.

[6] Shin'ya Nagasawa, editor: Premium Brand Strategies for Location and Traditional Industries - Technical Management that Generates Experience Value, Doyukan, 2009.

[7] Shin'ya Nagasawa, Takao Someya: Traditions and Innovations in the Veteran Brand Toraya - Experience Value Creation and Technical Management, Koyoshobo, 2007.
[8] Hideki Otsuka: 'There are No Recessions in 'Deep Emotion'Why Does Albion President Shoichi Kobayashi Distribute Flyers?,Kodansha, 2010.

[9] Shin'ya Nagasawa, editor: Sensibilities in Product Development, Japan Publishing Services, 2002

[10] Shin'ya Nagasawa, editor: Practice of sensibility product development, Japan Publishing Services, 2003 